\title{
Increasing Severity of Early-Onset Atopic Dermatitis, But Not Late-Onset, Associates with Development of Aeroallergen Sensitization and Allergic Rhinitis in Childhood
}

\author{
Ann-Marie Malby Schoos ${ }^{1}$, Bo Chawes ${ }^{1}$, Klaus Bønnelykke ${ }^{1}$, Jakob Stokholm ${ }^{1}$, Morten \\ Rasmussen $^{1}$, and Hans Bisgaard ${ }^{1}$ \\ ${ }^{1}$ Copenhagen Prospective Studies on Asthma in Childhood
}

July 8, 2021

\begin{abstract}
Background: Early exposure to allergens through a defect skin barrier has been proposed as a mechanism for inducing sensitization and development of allergic diseases. We hypothesized that early-onset, severe atopic dermatitis (AD) is associated with development of aeroallergen sensitization and allergic rhinitis. Methods: We included 368 children from the Copenhagen Prospective Studies on Asthma in Childhood 2000 (COPSAC 2000) at-risk mother-child cohort. AD was diagnosed prospectively based on Hanifin\&Rajka's criteria and severity assessed using the Scoring Atopic Dermatitis (SCORAD) index. Early-onset $\mathrm{AD}$ was defined as debut [?]1 year, late-onset as debut from 1-6 years. Aeroallergen sensitization and allergic rhinitis were diagnosed at ages 6-7 and 12 years. Associations between early-onset and late-onset AD and allergy endpoints were calculated using general estimating equations (GEE) models to compute the overall odds ratios (OR) for both time points. Results: Earlyonset $\mathrm{AD}$ (yes/no) and severity (SCORAD) were associated with development of aeroallergen sensitization during childhood; $\mathrm{GEE} \mathrm{OR}=1.68[1.08 ; 2.62], \mathrm{p}=0.02$ and 1.08 [1.03; 1.12], $\mathrm{p}<0.001$, whereas late-onset was not; $\mathrm{GEE} \mathrm{OR}=1.65[0.92 ; 2.94], \mathrm{p}=0.08$ and $1.01[0.97 ; 1.06], \mathrm{p}=0.55$. The same trend was seen for allergic rhinitis with significant association between early-onset $\mathrm{AD}$ and allergic rhinitis; GEE $\mathrm{OR}=1.56[1.01 ; 2.41], \mathrm{p}=0.04$ and severity; GEE $\mathrm{OR}=1.09$ [1.05; 1.13], $\mathrm{p}<0.001$, whereas late-onset $\mathrm{AD}$ showed no association. The effects on sensitization and rhinitis of early-onset vs. late-onset AD severity were significantly different: p-interaction sensitization $=0.03$ and p-interaction rhinitis $<0.01$. Conclusion: Increasing severity of early-onset $A D$, but not late-onset $\mathrm{AD}$, associates with aeroallergen sensitization and allergic rhinitis later in childhood.
\end{abstract}

Increasing Severity of Early-Onset Atopic Dermatitis, But Not Late-Onset, Associates with Development of Aeroallergen Sensitization and Allergic Rhinitis in Childhood

Ann-Marie Malby Schoos, MD, $\mathrm{PhD}^{1,2}$; Bo Lund Chawes, MD, PhD, DMSc ${ }^{1}$; Klaus Bønnelykke, MD, $\mathrm{PhD}^{1}$; Jakob Stokholm, MD, $\mathrm{PhD}^{1,2}$; Morten Arendt Rasmussen, $\mathrm{PhD}^{1}$; Hans Bisgaard, MD, DMSc${ }^{1}$

Affiliations: 1) COPSAC, Copenhagen Prospective Studies on Asthma in Childhood, Herlev and Gentofte Hospital, University of Copenhagen, Copenhagen, Denmark

2) Department of Pediatrics, Slagelse Sygehus, Slagelse, Denmark

Correspondence:

Professor Hans Bisgaard, MD, DMSc

E-mail: bisgaard@copsac.com

Website: www.copsac.com

Article type: Original article 
Word count: 2,959

Tables and figures: 4

Online Repository: Yes

Short title: Severe early-onset atopic dermatitis, aeroallergen sensitization and rhinitis

Authors Contributions: The guarantor of the study is HB, from conception and design to conduct of the study and acquisition of data, data analysis, and interpretation of data. AMS has written the first draft of the manuscript. All co-authors have provided important intellectual input and contributed considerably to the analyses and interpretation of the data. All authors guarantee that the accuracy and integrity of any part of the work have been appropriately investigated and resolved and all have approved the final version of the manuscript. The corresponding author had full access to the data and had final responsibility for the decision to submit for publication. No honorarium, grant, or other form of payment was given to any of the authors to produce this manuscript.

Source of Funding: All funding received by COPSAC is listed on www.copsac.com. The Lundbeck Foundation (Grant no R16-A1694); The Ministry of Health (Grant no 903516); Danish Council for Strategic Research (Grant no 0603-00280B) and The Capital Region Research Foundation have provided core support to the COPSAC research center.

Conflict of interest: All authors declare no potential, perceived, or real conflict of interest regarding the content of this manuscript. The funding agencies did not have any role in design and conduct of the study; collection, management, and interpretation of the data; or preparation, review, or approval of the manuscript. No pharmaceutical company was involved in the study.

Governance: We are aware of and comply with recognized codes of good research practice, including the Danish Code of Conduct for Research Integrity. We comply with national and international rules on the safety and rights of patients and healthy subjects, including Good Clinical Practice (GCP) as defined in the EU's Directive on Good Clinical Practice, the International Conference on Harmonisation's (ICH) good clinical practice guidelines and the Helsinki Declaration. Privacy is important to us which is why we follow national and international legislation on General Data Protection Regulation (GDPR), the Danish Act on Processing of Personal Data and the practice of the Danish Data Inspectorate.

\section{ABSTRACT}

Background: Early exposure to allergens through a defect skin barrier has been proposed as a mechanism for inducing sensitization and development of allergic diseases. We hypothesized that early-onset, severe atopic dermatitis (AD) is associated with development of aeroallergen sensitization and allergic rhinitis.

Methods : We included 368 children from the Copenhagen Prospective Studies on Asthma in Childhood $_{2000}\left(\mathrm{COPSAC}_{2000}\right)$ at-risk mother-child cohort. AD was diagnosed prospectively based on Hanifin\&Rajka's criteria and severity assessed using the Scoring Atopic Dermatitis (SCORAD) index. Early-onset $\mathrm{AD}$ was defined as debut [?]1 year, late-onset as debut from 1-6 years. Aeroallergen sensitization and allergic rhinitis were diagnosed at ages 6-7 and 12 years. Associations between early-onset and late-onset AD and allergy endpoints were calculated using general estimating equations (GEE) models to compute the overall odds ratios (OR) for both time points.

Results : Early-onset AD (yes/no) and severity (SCORAD) were associated with development of aeroallergen sensitization during childhood; GEE $\mathrm{OR}=1.68$ [1.08; 2.62], $\mathrm{p}=0.02$ and 1.08 [1.03; 1.12], $\mathrm{p}<0.001$, whereas late-onset was not; GEE $\mathrm{OR}=1.65[0.92 ; 2.94], \mathrm{p}=0.08$ and $1.01[0.97 ; 1.06], \mathrm{p}=0.55$. The same trend was seen for allergic rhinitis with significant association between early-onset $\mathrm{AD}$ and allergic rhinitis; GEE $\mathrm{OR}=1.56$ [1.01; 2.41], $\mathrm{p}=0.04$ and severity; GEE $\mathrm{OR}=1.09$ [1.05; 1.13], $\mathrm{p}<0.001$, whereas late-onset $\mathrm{AD}$ showed no association. The effects on sensitization and rhinitis of early-onset vs. late-onset AD severity were significantly different: $\mathrm{p}$-interaction sensitization $=0.03$ and $\mathrm{p}$-interaction ${ }_{\text {rhinitis }}<0.01$. 
Conclusion : Increasing severity of early-onset $\mathrm{AD}$, but not late-onset $\mathrm{AD}$, associates with aeroallergen sensitization and allergic rhinitis later in childhood.

Keywords: Atopic dermatitis; early-onset; late-onset; severity; SCORAD; Filaggrin mutation; aeroallergen sensitization; specific IgE; allergic rhinitis; childhoodAbbreviationsAD = Atopic Dermatitis

COPSAC $=$ Copenhagen Prospective Studies on Asthma in Childhood

SCORAD $=$ Scoring Atopic Dermatitis

$\mathrm{FLG}=$ Filaggrin

$\mathrm{OR}=$ Odds Ratio GEE $=$ General Estimating Equations sIgE $=$ specific IgE

\section{Introduction}

Atopic dermatitis (AD) is a chronic relapsing disease, which most often debuts in early childhood and remits later in childhood. It is characterized by defects in the barrier function due to an abnormal stratum corneum in both affected and nonaffected $\operatorname{skin}^{1,2}$. Several lines of evidence indicate that an epidermal barrier impairment in the skin of children with $\mathrm{AD}$ is involved in the development of allergic sensitization ${ }^{3,4}$. Recently, it has been proposed that early exposure to foods via the skin in children with AD may allow penetration of food allergens through the skin leading to development of sensitization and subsequent food allergy ${ }^{5,6}$. This is in contrast to an early, continuous oral exposure to some allergenic foods such as peanuts and egg, which may lead to development of immune tolerance and reduced risk of food allergy in young children $^{6-8}$.

The development of specific IgE ( $\mathrm{sIgE}$ ) to environmental allergens has also been associated with a defective skin barrier function ${ }^{4}$; e.g. one study showed association between increasing total epidermal water loss and prevalence of sensitization to aeroallergens ${ }^{4}$. Another study used a chemical sensitizer to show that sensitization through the skin in AD induced a persistent skewing towards antigen-specific Th2 responses regardless of Filaggrin $(F L G)$ mutation status ${ }^{3}$. $F L G$ is a key protein that assists in the final differentiation of the epidermis and formation of the skin barrier ${ }^{2}$. FLGmutation status leads to functional loss of barrier function in the skin and other mucosal surfaces ${ }^{2,9}$. A previous literature review described that up to $2 / 3$ of patients with $\mathrm{AD}$ will develop allergic rhinitis ${ }^{10}$, and particularly earlier debut of $\mathrm{AD}$ seemed to impose a higher risk. To our knowledge, no previous studies have investigated the association between AD severity and later development of aeroallergen sensitization and allergic rhinitis, and none included FLG mutation status.

We hypothesized that the epidermal barrier defect in early-onset, more severe AD in infancy compared to late-onset $\mathrm{AD}$ may facilitate penetration of aeroallergens via the skin and increase the risk of developing aeroallergen sensitization and allergic rhinitis in childhood. To test this hypothesis, we used data from the Copenhagen Prospective Studies on Asthma in Childhood ${ }_{2000}\left(\mathrm{COPSAC}_{2000}\right)$ at-risk mother-child cohort to determine whether early-onset vs. late-onset $\mathrm{AD}$ and severity of $\mathrm{AD}$ are associated with development of aeroallergen sensitization and allergic rhinitis at 6-7 and 12 years of age.

\section{Methods}

Design

COPSAC $_{2000}$ is a single-center, prospective clinical mother-child cohort study of 411 children born between August 1998 and December 2001 to mothers with a history of asthma ${ }^{11-13}$. The children were closely monitored from birth till age 12 years with 19 planned visits to the clinic (age 2 weeks, 1, 3, and 6 months and $1,11 / 2,2,21 / 2,3,31 / 2,4,41 / 2,5,51 / 2,6,61 / 2,7,9$ and 12 years), where the children were seen by a COPSAC research physician with dermatology training. Additional acute care visits were arranged upon onset of any asthma-, allergy-, or AD-related flare ups. Atopic disorders were diagnosed and monitored at these visits by the COPSAC physicians according to standard operating procedures.

Ethics 
The Copenhagen Ethics Committee (KF 01-289/96) and The Danish Data Protection Agency (2008-41-2434) approved the study, and oral and written informed consent was obtained from both parents at enrolment.

\section{Atopic dermatitis}

$\mathrm{AD}$ was diagnosed prospectively at scheduled and acute care visits at age 0-6 years (prior to evaluation of our outcomes) according to Hanifin and Rajka's criteria ${ }^{14}$ capturing age of debut and age of remission as previously detailed ${ }^{15,16}$. A diagnosis of $\mathrm{AD}$ required the presence of 3 of 4 major criteria and at least 3 of 23 minor signs. The following 4 minor signs were excluded: keratoconus and anterior sub-capsular cataracts, delayed blanch, and impaired cell-mediated immunity. The severity of AD was scored using the Scoring Atopic Dermatitis (SCORAD) index at scheduled and acute care visits ${ }^{17}$, ranging from 0 to 83 points (excluding the subjective components of pruritus and sleeplessness from the modified SCORAD index). As we saw the children at acute care visits whenever they had an AD flare-up, we were sure to capture the highest SCORAD value in the course of their disease.

Aeroallergen sensitization Assessment of sIgE levels in blood samples was done at age 6 and 12 years by an initial screening method (ImmunoCAP Phadiatop Infant and ImmunoCAP Phadiatop, Thermo Fisher Scientific, Uppsala, Sweden $)^{18}$ followed by analysis of individual allergen sIgE levels in screening positive samples towards birch, grass, mugwort, horse, dog, cat, house dust mites (D. pteronyssinus and D. farinae) and molds (Penicillium notatum, Cladosporium herbarum, Aspergillus fumigatus and Alternaria alternata). Sensitization was defined as values of $\operatorname{sIgE}[?] \quad 0.35 \mathrm{kU}_{\mathrm{A}} / \mathrm{L}^{13}$.

\section{Allergic rhinitis}

Allergic rhinitis was diagnosed at the COPSAC research unit at age 7 and 12 years based on a parental interview on history of symptoms. Allergic rhinitis was defined as substantial and reoccurring sneezing, blocked, itchy or runny nose severely affecting the wellbeing of the child in the past 12 months in periods without accompanying common cold or flu, and with congruence between symptoms, relevant exposure and aeroallergen sensitization (positive sIgE and/or skin prick test) ${ }^{19-22}$.

Filaggrin mutation Genotyping for common loss-of-function mutations in $F L G$, R501X, 2282del4, R2447X and S3247X was performed as previously described. ${ }^{2}$ A $F L G$ mutation carrier was defined as having at least one gene mutation.

\section{Statistical methods}

Age at $\mathrm{AD}$ debut ([?]/> $1 \mathrm{yr}$ ), aeroallergen sensitization (yes/no) and allergic rhinitis (yes/no) were categorized as binary variables. Severity of AD by means of SCORAD was included in the models as a continuous variable including the highest SCORAD level measured in the child (early-onset from 0-1 year and late-onset from 1-6 years).

Associations between AD (binary age at onset or continuous SCORAD) and aeroallergen sensitization and allergic rhinitis were analyzed by logistic regression analyses expressing results as odds ratios (OR) with $95 \%$ confidence intervals (CI). Furthermore, we used a logistic regression general estimating equations (GEE) model to compute the overall OR for allergy endpoints using compiled data from both time points and accounting for repeated measures. All results are calculated as crude and adjusted for potential confounders including sex, older siblings, maternal allergic rhinitis, paternal allergic rhinitis, breastfeeding and smoking during $3^{\text {rd }}$ trimester.

The analysis of whether the association between $\mathrm{AD}$ and later sensitization/allergic rhinitis depended on the $\mathrm{AD}$-debut age (yes/no) was analyzed using a logistic regression model where AD status is a three-level variable (early, late, never). The analysis of whether the association between AD and later sensitization/allergic rhinitis depended on the $\mathrm{AD}$-debut age (SCORAD) was based on two models using the quantitative measure of SCORAD as a predictor; one based on early debut, and one based on late debut. As all non-AD children had a SCORAD of 0, these are excluded from the analysis. From these models the slopes are compared using 
a Wald's tests associated with $\mathrm{H} 0: \mathrm{b}($ early $)=\mathrm{b}$ (late) which hence reveal whether the association between severity and $\mathrm{AR} / \mathrm{sIgE}$ is different between early and late $\mathrm{AD}$-debuts.

In the analyses of early-onset $\mathrm{AD}$ (debut[?]1yr, yes/no) we used all the other children as a control group, whereas in the analyses of late-onset $\mathrm{AD}$ (debut 1-6 years, yes/no) we excluded the children with an earlyonset $\mathrm{AD}$ debut from the control group.

We additionally stratified for $F L G$ mutation. Further, effect modification by $F L G$ was evaluated by second order interaction models by adding cross-products to the models.

All statistical analyses were performed with the statistical software package $\mathrm{R}$ version 4.0.2 and RStudio version 1.1.442 (RStudio Inc, Boston, MA, USA). Missing observations were treated as missing data. P-values $<0.05$ were considered statistically significant.

\section{Results}

Baseline

Assessment of allergic rhinitis was performed in 290 (71\%) of the 411 children at 7 years, in $353(86 \%)$ children at 12 years and in $368(90 \%)$ children at either 7 and/or 12 years. The latter defined the study population. Accordingly, assessment of aeroallergen sensitization was performed in $296(72 \%)$ of the children at 6 years, in $315(77 \%)$ children at 12 years and in $352(86 \%)$ children at either 6 and/or 12 years. Baseline characteristics including gender, socioeconomics, early life exposures, and allergic predisposition of the included and excluded children are outlined in Table 1 . The excluded children $(\mathrm{N}=43)$ had fewer older siblings than the included children (no older siblings: $68 \%$ vs. $60 \%, \mathrm{p}=0.04$ ), but did not differ with respect to the remaining baseline characteristics.

Age at onset of $A D$ and risk of sIgE aeroallergen sensitization

Aeroallergen sensitization measured by sIgE ([?] $\left.0.35 \mathrm{kU}_{\mathrm{A}} / \mathrm{L}\right)$ at 6 years was present in $29 / 84(35 \%)$ children with early-onset $\mathrm{AD}$ compared to $45 / 207$ (22\%) children without early-onset AD: $\mathrm{OR}=1.90$ [1.08; 3.31], $\mathrm{p}=0.02$. At 12 years, aeroallergen sensitization was present in $48 / 89(54 \%)$ vs. $92 / 215(43 \%)$ OR=1.56 $[0.95 ; 2.58], \mathrm{p}=0.08$. The GEE model of early-onset AD showed a compiled significantly increased OR for developing aeroallergen sensitization at the two timepoints of 1.68 [1.08; 2.62], $\mathrm{p}=0.02$ (Table 2 ).

In children with late-onset AD (1-6 years of age), aeroallergen sensitization at 6 years was diagnosed in $15 / 53(28 \%)$ compared to 28/145 (19\%) without late-onset AD: OR=1.65 [0.78; 3.38], $\mathrm{p}=0.18$. At 12 years, aeroallergen sensitization was present in $26 / 49(53 \%)$ vs. $54 / 136(40 \%)$ : OR=1.72 [0.89; 3.33], p=0.11. The GEE model showed a compiled borderline-significant OR for the two timepoints of 1.65 [0.92; 2.94], $\mathrm{p}=0.08$ (Table 2 ). Early-onset and late-onset AD imposed a similar risk of development of sIgE aeroallergen sensitization (p-interaction $=0.93$ ).

$A D$ severity and risk of aeroallergen sensitization

Among children with an early-onset AD, the highest severity score for AD (SCORAD) measured between 0-1 year showed associations with development of aeroallergen sensitization measured by sIgE. Per 1-point increase in SCORAD, the OR for aeroallergen sensitization at 6 years was 1.08 [1.03; 1.14], $\mathrm{p}<0.01$, and the OR for aeroallergen sensitization at 12 years was 1.08 [1.03; 1.13], $\mathrm{p}=<0.01$. The GEE model was significant with a compiled OR for the two timepoints of 1.08 [1.03; 1.12], $\mathrm{p}<0.001$. Contrary, among children with a late-onset $\mathrm{AD}$, the highest SCORAD measured from 1-6 years showed no significant associations with later development of aeroallergen sensitization (Table 2 ). Early-onset AD severity imposed a higher risk for development of sIgE aeroallergen sensitization than late-onset severity ( $\mathrm{p}$-interaction $=0.03$ ).

\section{$A D$ and risk of allergic rhinitis}

We assessed the associations between early-onset $\mathrm{AD}$, late-onset $\mathrm{AD}$, and $\mathrm{AD}$ severity and development of allergic rhinitis at 7 and 12 years (Table 3 ). Among children with early-onset AD, 17/83 (20\%) developed allergic rhinitis at 7 years $(\mathrm{OR}=2.22[1.09 ; 4.46], \mathrm{p}=0.025)$ and $38 / 98(38 \%)$ developed allergic rhinitis at 
12 years $(\mathrm{OR}=1.57[0.95 ; 2.56], \mathrm{p}=0.07)$. The GEE model showed a compiled OR for the two timepoints of $1.56[1.01 ; 2.41], \mathrm{p}=0.04$.

Among children with late-onset $\mathrm{AD}, 8 / 52(15 \%)$ developed allergic rhinitis at 7 years $(\mathrm{OR}=1.80$ [0.67; 4.58], $\mathrm{p}=0.22)$ and $21 / 60(35 \%)$ developed allergic rhinitis at 12 years $(\mathrm{OR}=1.36[0.71 ; 2.56], \mathrm{p}=0.35)$. The GEE model showed a compiled OR for the two timepoints of 1.76 [1.00; 3.10], $\mathrm{p}=0.05$ (Table 3 ). Early-onset and late-onset AD imposed a similar risk of development of allergic rhinitis (p-interaction=0.89). Similarly, early-onset AD severity (SCORAD) was associated with development of allergic rhinitis during childhood; GEE OR=1.09 [1.05; 1.13], $\mathrm{p}<0.001$, whereas late-onset severity was not; GEE OR=1.00 [0.96; 1.04], $\mathrm{p}=0.90$. Early-onset AD severity imposed a higher risk of allergic rhinitis than late-onset severity (p-interaction $<0.01)$.

Adjusting the results for sex, older siblings, maternal allergic rhinitis, paternal allergic rhinitis, breastfeeding and smoking during $3^{\text {rd }}$ trimester did not alter the results noteworthy (Table E1 and E2 ).

Filaggrin mutation The results for aeroallergen sensitization stratified by FLGmutation are shown in Table E3 in the Online Repository. When evaluating age at onset of AD and severity by SCORAD, FLGmutation did not seem to alter the results (Table E3 ).

The results for allergic rhinitis including stratification by FLGmutation are shown in Figure $\mathbf{1}$ and listed in Table E2. When evaluating age at onset of AD (Figure 1a ) FLGmutation did not seem to alter the results (p-interaction 7 years $=0.30$ and 12 years $=0.17$ ). However, when evaluating AD severity by SCORAD in children with early-onset AD, i.e., debut [?] 1 year, (Figure 1b )FLG positive children exhibited $24 \%$ $($ ORpos / ORneg $=1.34 / 1.08)$ and $14 \%($ ORpos / ORneg $=1.20 / 1.05)$ higher odds for the association between $\mathrm{AD}$ severity and development of allergic rhinitis at 7 and 12 years respectively in contrast to $F L G$ negative, indicating that this association is stronger among children withFLG mutation (p-interaction 0.06 and 0.055 , respectively). Due to low numbers, we were not able to investigate the association between SCORAD $>1$ year and allergy outcomes stratified by $F L G$ mutation status.

\section{Discussion}

\section{Primary findings}

In this longitudinal birth cohort study of 368 high-risk children, we found that increasing severity of earlyonset $\mathrm{AD}$ was associated with sensitization to aeroallergens and allergic rhinitis at 6-7 and 12 years, while severity of late-onset AD after age 1 year was not. These findings suggest that aeroallergens penetrate the skin inflamed from AD in infancy more so than later and that an early-onset vs. late-onset debut represent different endotypes of AD that differentially associate with subsequent risk of respiratory allergy in childhood.

\section{Strengths and limitations}

It is a major strength of the study that this is a prospective mother-child cohort design with 19 planned visits up until 12 years of age all including evaluations of AD at the COPSAC research clinic $^{11,15,16}$. Moreover, all children were additionally seen at the COPSAC clinic at acute visits for any skin-related symptoms, which minimized the risk of parental recall bias and ensured we captured the highest SCORAD values during the children's disease course. All AD diagnoses strictly followed standard operating procedures. This careful prospective follow-up is a significant strength enabling accurate diagnosis of AD including severity (SCORAD).

Another strength is the measurement of the outcomes, aeroallergen sensitization and allergic rhinitis, at two time-points (6-7 and 12 years), which ensured conclusions based on results from both early school-age and early teens.

All mothers had a history of asthma, i.e. study participants were at risk of respiratory allergy and asthma, which may limit the generalizability of our findings.

Interpretation 
We show that children with more severe, early-onset AD before age 1 year have an increased risk for developing sensitization to aeroallergens and allergic rhinitis compared to children with onset of AD after age 1 year. This is in agreement with some previous studies ${ }^{23-26}$ as most studies found higher frequencies of allergy outcomes in early-onset vs. late-onset $\mathrm{AD}^{27,28}$, whereas one study found no difference ${ }^{29}$ and two other studies only found a higher risk if children with early-onset also had persistent $\mathrm{AD}^{30,31}$. Further, the latter study found an increased risk of sensitization to aeroallergens at 18 years among children with late-onset $\mathrm{AD}^{31}$.

The varying findings in these previous studies can be due to several factors. Importantly, the severity of AD in early life seems to be the most important factor according to our study but was not assessed in previous studies. Also, the diagnosis of $\mathrm{AD}$ and allergic rhinitis was mostly based on questionnaires, and the evaluation of allergy outcomes was done at different time-points across the studies ranging from 4 to 18 years. Only one other study diagnosed sensitization and allergic rhinitis at several time points ${ }^{31}$, but with low complete follow-up rates of $52 \%$ at 7 years, $40 \%$ at 12 years and $39 \%$ at 18 years, in contrast to a follow-up rate of $71 \%$ at 7 years and $86 \%$ at 12 years in our study. None of the previous studies assessed $\mathrm{AD}$ severity, which showed significantly different effects in early-onset vs. late-onset in relation to both aeroallergen sensitization and allergic rhinitis.

The possible mechanisms driving the association between AD and respiratory allergy have previously been explained by an underlying Th2-skewed immune system ${ }^{10,32}$, which leads to an increased risk of both AD, asthma and allergic rhinitis. An inherent genetic susceptibility may also influence the risk of developing all three diseases. Thus, a GWAS study identified shared AD, asthma, and allergic rhinitis immune-related genetic variants, suggesting that these disorders may co-exist because they share genetic risk loci that result in dysregulation of immune-related genes ${ }^{33}$. However, this does not explain the mechanism behind age at onset and severity of AD and development of aeroallergen sensitization and allergic rhinitis.

More recently, the hypothesis explaining the association between AD and allergy has shifted to include a primary defect in the epidermal barrier in $\mathrm{AD}^{34}$. The epidermis provides an essential barrier to the external environment, preventing both water loss from the body and intrusion of infectious agents and allergens. When allergens are captured and processed by antigen-presenting Langerhans cells of the epidermis, they migrate to the draining lymph nodes and if not down-regulated, they can interact with naive $\mathrm{T}$ cells to promote Th2 immunity leading to allergies ${ }^{35}$. This epicutaneous sensitization has also been proposed to cause migration of Th2 memory cells from the skin to the bronchial lymphoid tissue, where subsequent inhalation of the sensitizing allergen causes a cellular and humoral response in the airways, resulting in symptoms of allergic rhinitis and asthma ${ }^{10}$. Finally, it has been proposed that chronic AD lesions may express thymic stromal lymphopoietin and other proinflammatory mediators, which increase the risk of developing allergic inflammation and sensitization in the lungs ${ }^{36}$.

Our study also showed a trend of higher risk of developing allergic rhinitis with increasing SCORAD among children with a FLGmutation compared to children without a mutation. Indeed, FLGmutation is known to lead to an impaired skin barrier, which is a plausible mechanistic explanation of the observed associations. To our knowledge no previous studies have investigated the role of FLGmutations in the relationship between $\mathrm{AD}$ age at onset, severity, and development of respiratory allergy. Our results should be interpreted with caution due to low numbers, and it would be interesting to investigate this association in a larger-scale study.

To ensure that early-onset AD was not present with concomitant allergic sensitization, and that reverse causation is not driving our results, we investigated early allergic sensitization at age 6 months. However, only 2 children were sensitized to an aeroallergen at this point - one from the early-onset AD group and one who never developed $\mathrm{AD}$, so that is not likely to alter our results.

Our study suggests programming in early life and that appropriate early interventions may hamper the progression of $\mathrm{AD}$ to aeroallergen sensitization and allergic rhinitis, especially in children with early-onset, more severe disease and FLG mutation. Following such thoughts, early strengthening of the epidermal barrier in high-risk infants using emollients before the onset of AD has been hypothesized to prevent development 
of $\mathrm{AD}$ and subsequent respiratory allergy, but this could not be demonstrated in two recent randomized controlled trials ${ }^{37,38}$.

To prevent development of aeroallergen sensitization and allergic rhinitis in children with early-onset, severe $\mathrm{AD}$, an alternative possible effective intervention may reside in modulating the immune response through manipulation of the route of earliest encounter with the allergen, along the same lines as has been shown with food allergens. Thus, early environmental exposure through the skin may lead to sensitization whereas early oral exposure may led to tolerance ${ }^{6-8}$ by stimulating regulatory T-cells induction and function in the gut $^{39}$. A murine study has supported this hypothesis ${ }^{40}$, and two human studies have tested this hypothesis in children using a sublingual immunotherapy mixture of house dust mite, cat and grass ${ }^{41}$ or house dust mite alone ${ }^{42,43}$. The studies failed to show any effect on development of allergic sensitization, which was also less influenced by early-onset and severity of AD in our study compared to allergic rhinitis, i.e., clinically relevant sensitization. Further, they had some weaknesses including high drop-out rates, lack of compliance, the children being too old at the beginning of the study, difficulty taking the sublingual immunotherapy correctly, and difficulty identifying children at high risk for developing AD. To establish whether early sublingual exposure to aeroallergens can prevent development of sensitization and allergic rhinitis in children with early-onset, severe $\mathrm{AD}$, randomized controlled trials taking all these factors into account are needed.

\section{Conclusion}

Our study suggests that increasing severity of early-onset AD is associated with the development of sensitization to aeroallergens and allergic rhinitis in childhood. Our findings imply that a skin barrier defect and/or skin inflammation from AD in infants may have important programming effects on development of respiratory allergy later in childhood. These findings call for a randomized controlled trial of early oral exposure to aeroallergens to reduce the risk for developing aeroallergen sensitization and allergic rhinitis in children, similar to what has been shown for primary prevention of food allergies.

\section{References}

1. Agrawal R, Woodfolk JA. Skin Barrier Defects in Atopic Dermatitis. Curr Allergy Asthma Rep. 2014;14:433.

2. Palmer CNA, Irvine AD, Terron-Kwiatkowski A, Zhao Y, Liao H, Lee SP, et al. Common loss-of-function variants of the epidermal barrier protein filaggrin are a major predisposing factor for atopic dermatitis. Nat Genet. 2006;38:441-6.

3. Newell L, Polak ME, Perera J, Owen C, Boyd P, Pickard C, et al. Sensitization via healthy skin programs Th2 responses in individuals with atopic dermatitis. J Invest Dermatol. 2013;133:2372-80.

4. Boralevi F, Hubiche T, Leaute-Labreze C, Saubusse E, Fayon M, Roul S, et al. Epicutaneous aeroallergen sensitization in atopic dermatitis infants - determining the role of epidermal barrier impairment. Allergy. 2008;63:205-10.

5. Fox DE, Lack G. Peanut allergy. Lancet. 1998;352:741.

6. Du Toit G, Roberts G, Sayre PH, Bahnson HT, Radulovic S, Santos AF, et al. Randomized trial of peanut consumption in infants at risk for peanut allergy. N Engl J Med. 2015;372:803-13.

7. Perkin MR, Logan K, Tseng A, Raji B, Ayis S, Peacock J, et al. Randomized Trial of Introduction of Allergenic Foods in Breast-Fed Infants. N Engl J Med. 2016;374:1733-43.

8. Natsume O, Kabashima S, Nakazato J, Yamamoto-Hanada K, Narita M, Kondo M, et al. Two-step egg introduction for prevention of egg allergy in high-risk infants with eczema (PETIT): a randomised, double-blind, placebo-controlled trial. Lancet. 2017;389:276-86.

9. Presland RB, Dale BA. Epithelial structural proteins of the skin and oral cavity: function in health and disease. Crit Rev Oral Biol Med. 2000;11:383-408. 
10. Spergel JM, Paller AS. Atopic dermatitis and the atopic march. J Allergy Clin Immunol. 2003;112:S118127.

11. Bisgaard H. The Copenhagen Prospective Study on Asthma in Childhood (COPSAC): design, rationale, and baseline data from a longitudinal birth cohort study. Ann Allergy Asthma Immunol. 2004;93:381-9.

12. Bisgaard H, Hermansen MN, Loland L, Halkjaer LB, Buchvald F. Intermittent inhaled corticosteroids in infants with episodic wheezing. N Engl J Med. 2006;354:1998-2005.

13. Bisgaard H, Hermansen MN, Buchvald F, Loland L, Halkjaer LB, Bonnelykke K, et al. Childhood asthma after bacterial colonization of the airway in neonates. N Engl J Med. 2007;357:1487-95.

14. Hanifin J, Rajka G. Diagnostic features of atopic dermatitis. Acta Derm Venereol. 1980;92:44-7.

15. Thorsteinsdottir S, Stokholm J, Thyssen JP, Norgaard S, Thorsen J, Chawes BL, et al. Genetic, Clinical, and Environmental Factors Associated With Persistent Atopic Dermatitis in Childhood. JAMA Dermatol. 2019;155:50-7.

16. If $\mathrm{R}, \mathrm{S} \mathrm{T}, \mathrm{S} \mathrm{N}, \mathrm{Bl} \mathrm{C}, \mathrm{K} \mathrm{B}, \mathrm{J}$ S, et al. Symptom burden of atopic dermatitis in early childhood assessed from daily monitoring of symptoms and topical steroid usage [Internet]. Journal of the American Academy of Dermatology. J Am Acad Dermatol; 2020 [cited 2020 Dec 2]. Available from: https://pubmed.ncbi.nlm.nih.gov/32950548/

17. Severity scoring of atopic dermatitis: the SCORAD index. Consensus Report of the European Task Force on Atopic Dermatitis. Dermatology (Basel). 1993;186:23-31.

18. Paganelli R, Ansotegui IJ, Sastre J, Lange CE, Roovers MH, de Groot H, et al. Specific IgE antibodies in the diagnosis of atopic disease. Clinical evaluation of a new in vitro test system, UniCAP, in six European allergy clinics. Allergy. 1998;53:763-8.

19. Braun-Fahrlander C, Wuthrich B, Gassner M, Grize L, Sennhauser FH, Varonier HS, et al. Validation of a rhinitis symptom questionnaire (ISAAC core questions) in a population of Swiss school children visiting the school health services. SCARPOL-team. Swiss Study on Childhood Allergy and Respiratory Symptom with respect to Air Pollution and Climate. International Study of Asthma and Allergies in Childhood. Pediatr Allergy Immunol. 1997;8:75-82.

20. Chawes BLK. Upper and lower airway pathology in young children with allergic- and non-allergic rhinitis. Dan Med Bull. 2011;58:B4278.

21. Chawes BLK, Bonnelykke K, Kreiner-Moller E, Bisgaard H. Children with allergic and nonallergic rhinitis have a similar risk of asthma. J Allergy Clin Immunol. 2010;126:567-573.e1-8.

22. Chawes BLK, Kreiner-Moller E, Bisgaard H. Objective assessments of allergic and nonallergic rhinitis in young children. Allergy. 2009;64:1547-53.

23. Gustafsson D, Sjoberg O, Foucard T. Development of allergies and asthma in infants and young children with atopic dermatitis-a prospective follow-up to 7 years of age. Allergy. 2000;55:240-5.

24. von Kobyletzki LB, Bornehag C-G, Hasselgren M, Larsson M, Lindstrom CB, Svensson A. Eczema in early childhood is strongly associated with the development of asthma and rhinitis in a prospective cohort. BMC Dermatol. 2012;12:11.

25. Wahn U, Warner J, Simons FER, de Benedictis FM, Diepgen TL, Naspitz CK, et al. IgE antibody responses in young children with atopic dermatitis. Pediatr Allergy Immunol. 2008;19:332-6.

26. Gustafsson D, Sjoberg O, Foucard T. Sensitization to food and airborne allergens in children with atopic dermatitis followed up to 7 years of age. Pediatr Allergy Immunol. 2003;14:448-52.

27. Kjellman B, Hattevig G. Allergy in early and late onset of atopic dermatitis. Acta Paediatrica. $1994 ; 83: 229-31$. 
28. Wan J, Mitra N, Hoffstad OJ, Gelfand JM, Yan AC, Margolis DJ. Variations in risk of asthma and seasonal allergies between early and late onset pediatric atopic dermatitis: a cohort study. J Am Acad Dermatol. 2017;77:634-40.

29. Mohrenschlager M, Schafer T, Huss-Marp J, Eberlein-Konig B, Weidinger S, Ring J, et al. The course of eczema in children aged 5-7 years and its relation to atopy: differences between boys and girls. The British Journal of Dermatology. 2006;154:505-13.

30. Carlsten C, Dimich-Ward H, Ferguson A, Watson W, Rousseau R, DyBuncio A, et al. Atopic dermatitis in a high-risk cohort: natural history, associated allergic outcomes, and risk factors. Annals of Allergy, Asthma \& Immunology. 2013;110:24-8.

31. Lowe AJ, Angelica B, Su J, Lodge CJ, Hill DJ, Erbas B, et al. Age at onset and persistence of eczema are related to subsequent risk of asthma and hay fever from birth to 18 years of age. Pediatr Allergy Immunol. 2017;28:384-90.

32. Kuo I-H, Yoshida T, Benedetto AD, Beck LA. The cutaneous innate immune response in patients with atopic dermatitis. Journal of Allergy and Clinical Immunology. 2013;131:266-78.

33. Ferreira MA, Vonk JM, Baurecht H, Marenholz I, Tian C, Hoffman JD, et al. Shared genetic origin of asthma, hay fever and eczema elucidates allergic disease biology. Nat Genet. 2017;49:1752-7.

34. Zheng T, Yu J, Oh MH, Zhu Z. The atopic march: progression from atopic dermatitis to allergic rhinitis and asthma. Allergy Asthma Immunol Res. 2011;3:67-73.

35. McGrath JA, Uitto J. The filaggrin story: novel insights into skin-barrier function and disease. Trends Mol Med. 2008;14:20-7.

36. Demehri S, Morimoto M, Holtzman MJ, Kopan R. Skin-derived TSLP triggers progression from epidermal-barrier defects to asthma. PLoS Biol. 2009;7:e1000067.

37. Chalmers JR, Haines RH, Bradshaw LE, Montgomery AA, Thomas KS, Brown SJ, et al. Daily emollient during infancy for prevention of eczema: the BEEP randomised controlled trial. The Lancet. 2020;395:96272 .

38. Skjerven HO, Rehbinder EM, Vettukattil R, LeBlanc M, Granum B, Haugen G, et al. Skin emollient and early complementary feeding to prevent infant atopic dermatitis (PreventADALL): a factorial, multicentre, cluster-randomised trial. Lancet. 2020;395:951-61.

39. Grindebacke H, Stenstad H, Quiding-Jarbrink M, Waldenstrom J, Adlerberth I, Wold AE, et al. Dynamic development of homing receptor expression and memory cell differentiation of infant CD4+CD25high regulatory T cells. J Immunol. 2009;183:4360-70.

40. Sato MN, Carvalho AF, Silva AO, MacIel M, Fusaro AE, Duarte AJ. Oral tolerance induced to house dust mite extract in naive and sensitized mice: evaluation of immunoglobulin $\mathrm{G}$ anti-immunoglobulin $\mathrm{E}$ autoantibodies and IgG-IgE complexes. Immunology. 1998;95:193-9.

41. Holt PG, Sly PD, Sampson HA, Robinson P, Loh R, Lowenstein H, et al. Prophylactic use of sublingual allergen immunotherapy in high-risk children: a pilot study. J Allergy Clin Immunol. 2013;132:991-993.e1.

42. Zolkipli Z, Roberts G, Cornelius V, Clayton B, Pearson S, Michaelis L, et al. Randomized controlled trial of primary prevention of atopy using house dust mite allergen oral immunotherapy in early childhood. J Allergy Clin Immunol. 2015;136:1541-1547.e11.

43. Alviani C, Roberts G, Moyses H, Pearson S, Larsson M, Zolkipli Z, et al. Follow-up, 18 months off house dust mite immunotherapy, of a randomized controlled study on the primary prevention of atopy. Allergy. $2019 ; 74: 1406-8$. 
Figure 1: Associations between early-onset AD ([?] 1 year) and late-onset AD (1-6 years) and allergic rhinitis (AR) at 7 and 12 years. $\mathrm{AD}$ is either defined as a binary variable (yes/no) (a) or a continuous variable expressed as a severity score (SCORAD) (b)for AD. All the results are stratified for Filaggrin (FLG ) mutation. The numbers indicate children with the variable present and evaluated outcome.

\section{Hosted file}

image1.emf available at https://authorea.com/users/424596/articles/529651-increasingseverity-of-early-onset-atopic-dermatitis-but-not-late-onset-associates-withdevelopment-of-aeroallergen-sensitization-and-allergic-rhinitis-in-childhood

Hosted file

image2.emf available at https://authorea.com/users/424596/articles/529651-increasingseverity-of-early-onset-atopic-dermatitis-but-not-late-onset-associates-withdevelopment-of-aeroallergen-sensitization-and-allergic-rhinitis-in-childhood

$\mathrm{AD}=$ Atopic Dermatitis SCORAD $=$ Scoring Atopic Dermatitis OR = Odds Ratio NA = Not Available, too few children to generate an $\mathrm{OR}$ AR $=$ Allergic Rhinitis $F L G=$ Filaggrin

Table 1: Baseline characteristics of included children who were assessed for allergic rhinitis at 7 and/or 12 years and excluded children.

\begin{tabular}{llll}
\hline Characteristics & N (Total) & Included & Exclu \\
\hline & 411 & 368 & 43 \\
Gender & Gender & Gender & Gend \\
Male N (\%) & 411 & $182(50 \%)$ & $21(49$ \\
Socioeconomic factors & Socioeconomic factors & Socioeconomic factors & Socio \\
Social circumstances*, mean (SD) & 382 & $0.02(1.0)$ & -0.25( \\
Smoking during third trimester & Smoking during third trimester & Smoking during third trimester & Smok \\
Yes N (\%) & 411 & $53(14 \%)$ & $10(23$ \\
Older siblings & Older siblings & Older siblings & Older \\
No older siblings N (\%) & 385 & $212(60 \%)$ & $21(68$ \\
1 older N (\%) & & $103(29 \%)$ & $5(16 \%$ \\
2 older N (\%) & & $26(7.3 \%)$ & $1(3.2 \%$ \\
3 older N (\%) & $13(3.7 \%)$ & $4(13 \%$ \\
Maternal allergic disposition & Maternal allergic disposition & Maternal allergic disposition & Mater \\
Asthma: Yes N (\%) & 411 & $368(100 \%)$ & $43(10)$ \\
Allergic rhinitis: Yes N (\%) & 410 & $275(75 \%)$ & $35(81)$ \\
AD: Yes N (\%) & 411 & $174(47 \%)$ & $24(56$ \\
Paternal allergic disposition & Paternal allergic disposition & Paternal allergic disposition & Pater \\
Asthma: Yes N (\%) & 399 & $65(18 \%)$ & $3(7.1 \%)$ \\
Allergic rhinitis: Yes N (\%) & 397 & $122(34 \%)$ & $8(20)$ \\
AD: Yes N (\%) & $44(12 \%)$ & $8(20 \%$ \\
Allergic disposition & 397 & & $4(12 \%$ \\
Filaggrin mutation: Yes N (\%) & 395 & $46(13 \%)$ & $96(70$ \\
Solely breastfed, mean days (SD) & 354 & $248(153)$ & $227(1)$ \\
Total breastfed, mean days (SD) & 395 & &
\end{tabular}

* Social circumstances are correlated to household income $(\mathrm{r}=0.73, \mathrm{p}<0.001)$, to maternal level of education $(\mathrm{r}=0.68, \mathrm{p}<0.001)$ and to maternal age $(\mathrm{r}=0.75, \mathrm{p}<0.001)$. For further information, see the Online Repository

Table 2: Associations between early-onset AD ([?] 1 year) and late-onset AD ( $>1$ year) and allergic sensitization at 7 and 12 years. AD is either defined as a dichotomous variable (yes/no) or a continuous 
variable expressed as a severity score (SCORAD) for AD. The GEE $\$$ model computes the overall OR for allergic rhinitis using compiled data from both time points.

\begin{tabular}{llll}
\hline & Allergic sensitization $\left(\mathrm{sIgE}^{*}\right)$ at $6 \mathrm{yrs}$ & Allergic sensitization $(\mathrm{sIgE} *)$ at $6 \mathrm{yrs}$ & Allergic sensitization $\left(\mathrm{sIgE}^{*}\right)$ at \\
\hline Debut & $\mathrm{N}^{\wedge}$ & OR & $95 \%$ CI \\
AD yes $/$ no & AD yes/no & AD yes/no & AD yes/no \\
$1 \mathrm{yr}$ & $84 / 291(29 \%)$ & 1.90 & {$[1.08 ; 3.31]$} \\
$>1 \mathrm{yr}$ & $53 / 198(27 \%)$ & 1.65 & {$[0.78 ; 3.38]$} \\
SCORAD & SCORAD & SCORAD & SCORAD \\
$1 \mathrm{yr}$ & $72 / 291(25 \%)$ & 1.08 & {$[1.03 ; 1.14]$} \\
$>1 \mathrm{yr}$ & $67 / 198(34 \%)$ & 1.04 & {$[0.99 ; 1.09]$} \\
\hline
\end{tabular}

$\S$ Logistic regression General Estimating Equations.

* sIgE [?] $0.35 \mathrm{kUA} / \mathrm{L}$ to any aeroallergen

Table 3: Associations between early-onset AD ([?] 1 year) and late-onset $\mathrm{AD}$ (> 1 year) and allergic rhinitis at 7 and 12 years. AD is either defined as a binary variable (yes/no) or a continuous variable expressed as a severity score (SCORAD) for AD. The GEE* model computes the overall OR for allergic rhinitis using compiled data from both time points.

\begin{tabular}{|c|c|c|c|c|}
\hline & Allergic Rhinitis at 7yrs & Allergic Rhinitis at 7yrs & Allergic Rhinitis at 7yrs & Allergic Rhinitis at 7yrs \\
\hline Debut & $\mathrm{N}^{\wedge}$ & OR & $95 \%$ CI & p-value \\
\hline $\mathrm{AD}$ yes/no & $\mathrm{AD}$ yes/no & $\mathrm{AD}$ yes/no & $\mathrm{AD}$ yes/no & $\mathrm{AD}$ yes/no \\
\hline $1 \mathrm{yr}$ & $83 / 285(29 \%)$ & 2.22 & {$[1.09 ; 4.46]$} & 0.03 \\
\hline$>1 \mathrm{yr}$ & $52 / 194(27 \%)$ & 1.80 & {$[0.67 ; 4.58]$} & 0.22 \\
\hline SCORAD & SCORAD & SCORAD & SCORAD & SCORAD \\
\hline $1 \mathrm{yr}$ & $71 / 285(25 \%)$ & 1.11 & {$[1.05 ; 1.18]$} & $<0.001$ \\
\hline$>1 \mathrm{yr}$ & $66 / 194(34 \%)$ & 0.99 & {$[0.92 ; 1.06]$} & 0.85 \\
\hline
\end{tabular}

the late-onset group $(>1 \mathrm{yr})$ the total $\mathrm{N}$ is lower as we excluded the children with early-onset $\mathrm{AD}$ from those calculations.

* Logistic regression General Estimating Equations.

\section{Online Repository}

Baseline table of original information used to derive the measure of social circumstances.

\begin{tabular}{llll}
\hline & & COPSAC $_{\mathbf{2 0 0 0}}$ & COPSAC $_{\mathbf{2 0 0 0}}$ \\
\hline & Variable type & $\begin{array}{c}\text { categorical: n (\%) } \\
\text { numeric: mean (SD) }\end{array}$ & Missing data \\
$\begin{array}{l}\text { Household income } \\
\text { (Euros/year) }\end{array}$ & cat & 29 \\
Below 54.000 & & $120(31.41)$ & \\
$54.000-81.000$ & & $153(40.05)$ & \\
$81.000-108.000$ & & $76(19.90)$ & \\
$108.000-134.000$ & & $22(5.76)$ & \\
Above 134.000 & cat & & 29 \\
Maternal education & &
\end{tabular}




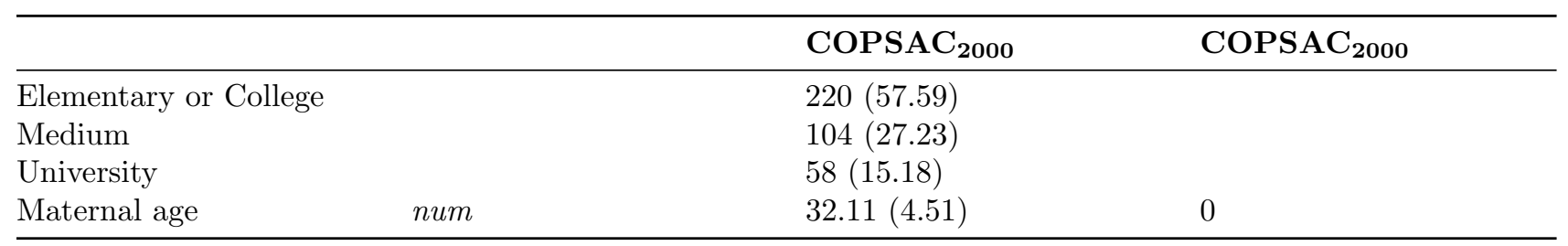

Social circumstances are correlated to household income $(\mathrm{r}=0.73, \mathrm{p}<0.001)$, to maternal level of education $(\mathrm{r}=0.68, \mathrm{p}<0.001)$ and to maternal age $(\mathrm{r}=0.75, \mathrm{p}<0.001)$.

Table E1: Associations between early-onset AD ([?] 1 year) and late-onset AD ( $>1$ year) and allergic sensitization at 6 and 12 years. $\mathrm{AD}$ is either defined as a dichotomous variable (yes/no) or a continuous variable expressed as a severity score (SCORAD) for $\mathrm{AD}$. The $\mathrm{GEE}^{\S}$ model computes the overall aOR for allergic sensitization using compiled data from both time points. Analyses are adjusted for sex, older siblings, maternal allergic rhinitis, paternal allergic rhinitis, breastfeeding and smoking during $3^{\text {rd }}$ trimester.

\begin{tabular}{llll}
\hline & Allergic sensitization $\left(\mathrm{sIgE}^{*}\right)$ at $6 \mathrm{yrs}$ & Allergic sensitization $\left(\mathrm{sIgE}^{*}\right)$ at $6 \mathrm{yrs}$ & Allergic sensitization $\left(\mathrm{sIgE}^{*}\right)$ at \\
\hline Debut & $\mathrm{N}^{\wedge}$ & $\mathrm{aOR}$ & $95 \% \mathrm{CI}$ \\
AD yes $/$ no & AD yes/no & AD yes $/$ no & AD yes/no \\
$1 \mathrm{yr}$ & $84 / 291(29 \%)$ & 1.96 & {$[1.09 ; 3.51]$} \\
$>1 \mathrm{yr}$ & $53 / 198(27 \%)$ & 1.84 & {$[0.85 ; 3.92]$} \\
SCORAD & SCORAD & SCORAD & SCORAD \\
$1 \mathrm{yr}$ & $72 / 291(25 \%)$ & 1.09 & {$[1.03 ; 1.16]$} \\
$>1 \mathrm{yr}$ & $67 / 198(34 \%)$ & 1.06 & {$[1.00 ; 1.13]$} \\
\hline
\end{tabular}

$\S$ Logistic regression General Estimating Equations.

* sIgE [?] $0.35 \mathrm{kUA} / \mathrm{L}$ to any aeroallergen

Table E2: Associations between early-onset AD ([?] 1 year) and late-onset AD (> 1 year) and allergic rhinitis at 7 and 12 years. $\mathrm{AD}$ is either defined as a binary variable (yes/no) or a continuous variable expressed as a severity score (SCORAD) for AD. The GEE* model computes the overall aOR for allergic rhinitis using compiled data from both time points. Analyses are adjusted for sex, older siblings, maternal allergic rhinitis, paternal allergic rhinitis, breastfeeding and smoking during $3^{\text {rd }}$ trimester.

\begin{tabular}{|c|c|c|c|c|}
\hline & Allergic Rhinitis at 7yrs & Allergic Rhinitis at 7yrs & Allergic Rhinitis at 7yrs & Allergic Rhinitis at $7 \mathrm{yrs}$ \\
\hline Debut & $\mathrm{N}^{\wedge}$ & $\mathrm{aOR}$ & $95 \%$ CI & p-value \\
\hline $\mathrm{AD}$ yes/no & $\mathrm{AD}$ yes/no & $\mathrm{AD}$ yes/no & $\mathrm{AD}$ yes/no & $\mathrm{AD}$ yes/no \\
\hline $1 \mathrm{yr}$ & $83 / 285(29 \%)$ & 2.02 & {$[0.97 ; 4.18]$} & 0.06 \\
\hline$>1 \mathrm{yr}$ & $52 / 194(27 \%)$ & 2.13 & {$[0.77 ; 5.69]$} & 0.13 \\
\hline SCORAD & SCORAD & SCORAD & SCORAD & SCORAD \\
\hline $1 \mathrm{yr}$ & $71 / 285(25 \%)$ & 1.12 & {$[1.05 ; 1.23]$} & $<0.01$ \\
\hline$>1 \mathrm{yr}$ & $66 / 194(34 \%)$ & 0.98 & {$[0.89 ; 1.07]$} & 0.72 \\
\hline
\end{tabular}

the late-onset group ( $>$ 1yr) the total $\mathrm{N}$ is lower as we excluded the children with early-onset $\mathrm{AD}$ from those calculations.

* Logistic regression General Estimating Equations.

Table E3: Associations between early-onset AD ([?] 1 year) and late-onset AD (> 1 year) and allergic 
sensitization at 6 and 12 years (positive sIgE) stratified by $F L G$ mutation. AD is either defined as a dichotomous variable (yes/no) or a continuous variable expressed as a severity score (SCORAD) for AD.

\begin{tabular}{|c|c|c|c|}
\hline & Allergic sensitization $\left(\operatorname{sIg} \mathrm{E}^{*}\right)$ at $6 \mathrm{yrs}$ & Allergic sensitization $\left(\mathrm{sIgE}^{*}\right)$ at $6 y \mathrm{ys}$ & Allergic sensitization $(\mathrm{s}$ \\
\hline$F L G^{\S}$ & $\mathrm{N}^{\wedge}$ & OR & $95 \% \mathrm{CI}$ \\
\hline $\mathrm{AD}$ yes/no [?] $1 \mathrm{yr}$ & $\mathrm{AD}$ yes/no [?] $1 \mathrm{yr}$ & $\mathrm{AD}$ yes/no [?] $1 \mathrm{yr}$ & $\mathrm{AD}$ yes/no [?] $1 \mathrm{yr}$ \\
\hline Pos & $17 / 38(45 \%)$ & 2.25 & {$[0.61 ; 8.72]$} \\
\hline Neg & $67 / 252(27 \%)$ & 1.70 & {$[0.89 ; 3.19]$} \\
\hline $\mathrm{AD}$ yes $/$ no $>1 \mathrm{yr}$ & $\mathrm{AD}$ yes $/$ no $>1$ yr & $\mathrm{AD}$ yes $/$ no $>1 \mathrm{yr}$ & $\mathrm{AD}$ yes $/$ no $>1$ yr \\
\hline Pos & $5 / 20(25 \%)$ & 4.13 & {$[0.51 ; 41.8]$} \\
\hline Neg & $47 / 177(27 \%)$ & 1.35 & {$[0.58 ; 2.98]$} \\
\hline
\end{tabular}

\begin{tabular}{llll}
\hline & Allergic sensitization (sIgE*) at 6yrs & Allergic sensitization (sIgE*) at 6yrs & Allergic sensitization (sI \\
\hline$F L G^{\S}$ & $\mathrm{N}^{\wedge}$ & OR & $95 \%$ CI \\
SCORAD [?] $1 \mathrm{yr}$ & SCORAD [?] 1 yr & SCORAD [?] 1 yr & SCORAD [?] $1 \mathrm{yr}$ \\
Pos & $17 / 38(45 \%)$ & 1.14 & {$[1.00 ; 1.38]$} \\
Neg & $55 / 252(22 \%)$ & 1.07 & {$[1.01 ; 1.13]$} \\
SCORAD $>1$ yr & SCORAD $>1 \mathrm{yr}$ & SCORAD $>1 \mathrm{yr}$ & SCORAD $>1 \mathrm{yr}$ \\
Pos & & & NA \\
Neg & $61 / 177(34 \%)$ & 1.05 & {$[0.99 ; 1.11]$} \\
\hline
\end{tabular}

* $\operatorname{sIgE}[?] 0.35 \mathrm{kUA} / \mathrm{L}$ to any aeroallergen

$\S F L G=$ Filaggrin mutation

Table E2: Associations between early-onset AD ([?] 1 year) and late-onset $\mathrm{AD}$ (> 1 year) and allergic rhinitis at 7 and 12 years stratified by $F L G$ mutation. AD is either defined as a dichotomous variable (yes/no) or a continuous variable expressed as a severity score (SCORAD) for AD.

\begin{tabular}{lllll}
\hline & Allergic rhinitis at 6yrs & Allergic rhinitis at 6yrs & Allergic rhinitis at 6yrs & Allergic rhinitis at 6yrs \\
\hline$F L G^{\S}$ & $\mathrm{N}^{\wedge}$ & OR & $95 \% \mathrm{CI}$ & p-value \\
AD yes/no [?] $1 \mathrm{yr}$ & AD yes/no [?] 1 yr & AD yes/no [?] 1 yr & AD yes/no [?] $1 \mathrm{yr}$ & AD yes/no [?] $1 \mathrm{yr}$ \\
Pos & $17 / 38(45 \%)$ & 3.27 & {$[0.71 ; 18.1]$} & 0.14 \\
Neg & $66 / 246(27 \%)$ & 1.92 & {$[0.83 ; 4.30]$} & 0.12 \\
AD yes/no $>1 \mathrm{yr}$ & AD yes/no $>1 \mathrm{yr}$ & AD yes/no $>1 \mathrm{yr}$ & AD yes $/$ no $>1 \mathrm{yr}$ & AD yes $/$ no $>1 \mathrm{yr}$ \\
Pos & & & NA & \\
Neg & $46 / 173(27 \%)$ & 1.17 & {$[0.35 ; 3.36]$} & 0.78 \\
\hline
\end{tabular}

\begin{tabular}{lllll}
\hline & Allergic rhinitis at 6yrs & Allergic rhinitis at 6yrs & Allergic rhinitis at 6yrs & Allergic rhinitis at 6yrs \\
\hline$F L G^{\S}$ & $\mathrm{N}^{\wedge}$ & OR & $95 \%$ CI & p-value \\
SCORAD [?] 1 yr & SCORAD [?] 1 yr & SCORAD [?] 1 yr & SCORAD [?] 1 yr & SCORAD [?] 1 yr \\
Pos & $17 / 38(45 \%)$ & 1.34 & {$[1.09 ; 2.04]$} & 0.05 \\
Neg & $54 / 246(22 \%)$ & 1.08 & {$[1.02 ; 1.16]$} & 0.01 \\
SCORAD $>1$ yr & SCORAD $>1 \mathrm{yr}$ & SCORAD $>1 \mathrm{yr}$ & SCORAD $>1 \mathrm{yr}$ & SCORAD $>1 \mathrm{yr}$ \\
Pos & & & NA & \\
Neg & & NA & \\
\hline
\end{tabular}


$\S F L G=$ Filaggrin mutation 